\title{
NOVELTIES IN \\ SWEDISH AUTOMOBILE INSURANCE RATING
}

by

GUNNAR LANTELI

Stockholm (Sweden)

On March Ioth, I96I, the majority of the Swedish Automobile Insurance Companies introduced a remarkable novelty in automobile insurance rating, a rating plan for private passenger cars partly based on a recent statistical investigation of the variation of risk with some characteristics of the driver and the vehicle. These characteristics had not until then been used for classification purposes, nor had they been studied in our current experience.

For a long time the Swedish rating plan has classified private passenger cars by geographical district (3), merit class or ,, bonus class" ( 7 ) and (for Auto Physical Damage only) horsepowers (8). Teetotallers enjoy a special discount of $20 \%$.

In spite of this rather far-going subdivision, founded on an elaborate statistical experience it was quite obvious that some important element was missing, as different companies operating in the same market showed significantly deviating underwriting experience. The tariff association ,Svenska Bilförsäkringsföreningen” $(\mathrm{SBF})$ and some other independent companies agreed to make a special investigation to find the cause of this adversity. A small committee was appointed to handle the question. From the start it was clear that some kind of inquiry had to be made among the policy holders of the participating companies. The information we needed was if and how different attributes such as sex, age, marital status, occupation, use of the car, annual mileage etc. influenced the risk. To inquire all of our private passenger carowners would have been too costly so we had to choose between a random sample and some other kind of limitation.

In neither case we could expect to calculate reliable rates so we had to content ourselves with trying to establish more or less significant relations between different attributes and the claim fre- 
quency. It would be favourable to pick out policy holders belonging to a group that was as homogenous as possible with regard to geographical district. Therefore we at last decided to select the Stockholm area, which of all our districts has the greatest number of private passenger cars, 80 ooo of which were insured with the companies in question.

A translation of the questionaire is shown in Appendix I. They were sent out about Febr. Ist, I 960 and by the end of March about 80 per cent had been returned. The unusually high reply-quotient was probably partly due to the fact that rewards had been promised among those who replied within ro days. (Cf Appendix r).

After examining and in some cases completing the forms, the data were transferred to punch cards which in turn were matched with the ordinary statistical cards for insurances and claims. The reply-codes were then transferred to the insurance-cards and the claim-cards. Hereafter sorting and tabulating took place.

For SBF the total number of car years exposed in the group under investigation amounted to 68748 . Of these $5 \mathrm{I} 213$ or 75 per cent represented policy holders who had given a satisfactory (i.e. complete and reasonable) answer to our questions. The percentage is slightly less than the original reply percentage owing to the fact that policies which had expired during the year I959 were not included in the inquiry, while their car years exposed were counted for.

Because the investigation had to be performed so soon after the end of the accident year we had mainly to rely on the claim frequency as a risk measure. The "No-reply-group" showed a considerably higher claim frequency than the "Reply-group" but this was not deemed to affect the validity of the results because these were expected to be merely of a relative nature as explained above.

The study comprised third party liability coverage as well as collision coverage but in the following I will confine myself to third party liability which is compulsory in Sweden under the name of traffic insurance.

After a thorough checking and rectification of the collected data we proceeded to classify it by all recorded arguments one at a time or two or three in combination. The claim frequency and the average value of the measurable quantities were calculated. In 
this way we got a mapping of the correlation between different risk attributes, and above all the very interesting information we were looking for, namely how the claim frequency varied with these attributes.

I can here only give a hint of some of our more or less remarkable findings (Appendix 2). An explanation may be necessary regarding mileage I959. Those policy holders who had not owned a car during the whole of 1959 were requested to tell us for how long time they had been car-owners and their mileage thus could be evaluated on a yearly basis.

It is quite clear that there must be a strong dependence between such attributes as the policy holder's age and the number of years he has had a driver's license. The same applies to the no-claim discount or ,bonus", which is liable to increase with growing age for natural reasons, as it takes at least six years to reach the highest bonus class in the Swedish bonus system. The investigation revealed on the other hand that the annual mileage steadily was decreasing with growing age. All these circumstances enforce certain precautions in order to avoid counting for the same original risk factor more than once in the rating system. It would lead too far going into the necessary but troublesome calculations involved in this matter. Bertil Almer has many years ago worked out methods to separate the effect of simultaneously operating risk factors (Cf. Transactions XVth International Congress of Actuaries New York Volume II p. 344-349). It is essentially the same method that Bailey and Simon have described in the ASTIN Bulletin Vol. I Part IV p. 202-217.

After a separation process of this kind it was possible to decide upon the relative importance of the different attributes. Constructing a rating system is not merely presenting the right schedules, it is also necessary to imagine if and how it will work. This is mainly a practical task but the actuary has to take part in it because it very often comes to weighing the theoretical demand against the practical difficulties. I am not intending to go further into this subject but will conclude with a short description of the ratingsystem that has emerged and is now on trial.

As before private passenger automobiles are classified by geographical district and bonus class. A subdivision with regard to 
horse-powers in 8 classes has since 1958 been practised for collision coverage. It has now been extended to third party liability but with a constant premium rate for the five top classes. The most important feature of the new schedule is the subdivision with regard to annual mileage in 3 classes:

$\begin{array}{rr} & \text { Rate relation } \\ \text { I up to } \quad \text { I0 } 000 \mathrm{~km} & 80 \\ \text { II IO } 000-25000 \mathrm{~km} & \text { I00 } \\ \text { III } 2500 \mathrm{k}-\quad \mathrm{km} & \text { I20 }\end{array}$

This scale does not - as I have mentioned previously - mirror the actual risk relations but is probably underestimating the differences. The reason for this is that we must be cautious before our experience is quite stabilized. The last new attribute that is involved in our rating system is age or may I say - adultness. This is managed so that a new policy starts in bonus class $2(20 \%$ discount) if the policy holder is $\mathbf{2 5}$ or older or if he has had a driver's license for at least 3 years, otherwise he must start in bonus class I (no discount).

Some people are afraid of the complications that the annual mileage may induce. The pure technical complications as to the calculation of the correct premium due cannot in my opinion be very serious in these days when any insurance company of some importance has its own computer or at least an advanced punch card installation. Harder to overcome is the difficulty in preventing misuse of the system. It will of course not be possible to avoid a certain degree of intentional underestimation of the mileage for the year ahead, but our hope is that this will not happen in too many cases. On the insurance application the insured is compelled to note the setting of the mileage meter. Every time he pays his renewal premium he also is urged to notify us about the setting and when an accident occurs it is mandatory for the garage to advice the company about the same thing. Thus we hope to a certain extent to be able to avoid a too frequent misuse but time alone will tell if we are right in this hope. An actual test and a statistical follow-up is the only way to get a definit answer to the question, if the new classification system is here to stay. From the theoretical standpoint at least I myself think it is a great improvement. 
Page I.

Appendix 1 .

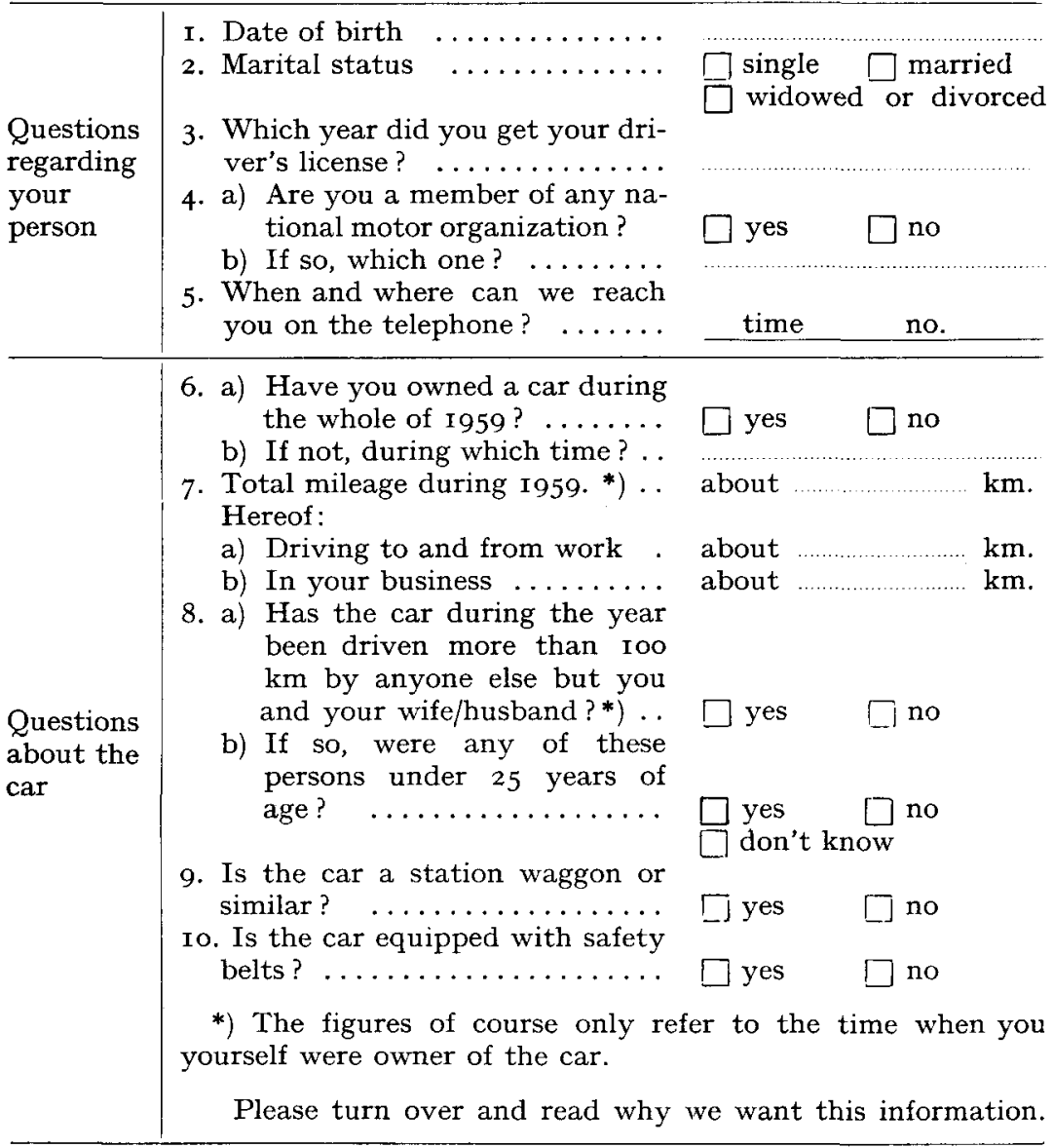

Page 2.

To the policy holder.

Investigation concerning the habits of driving etc.

After conference with the National Private Insurance Inspectorate, the $\mathrm{Na}$ tional Society for Traffic Security and the great motor organizations the Svenska Bilförsäkringsföreningen (SBF) has decided to make a statistical investigation of the habits of driving among the private car owners. The investigation is limited to the Stockholm area.

We should very much appreciate if you could help us with this investigation by answering the questions on the opposite side if possible within Io days. Please send your answer to us in the enclosed envelope without 
postage. It is very important that the information is correct and clear and also that we receive as many answers as possible. The answers will be handled confidentially.

In order to avoid the cost of reminding you once more the insurance companies taking part in this investigation will give Ioo rewards to those who have given answers within ro days. The reward will be an approved safety belt or some other car equipment of equivalent value. The names of those rewarded will be published in the motor press.

We hope that it will not cause you too much trouble to fill up this formula and we thank you in advance for your valuable contribution.

Yours sincerely

\section{APPENDIX 2}

Claim frequency $\%$ and Average mileage $1959(\mathrm{~km})$ by

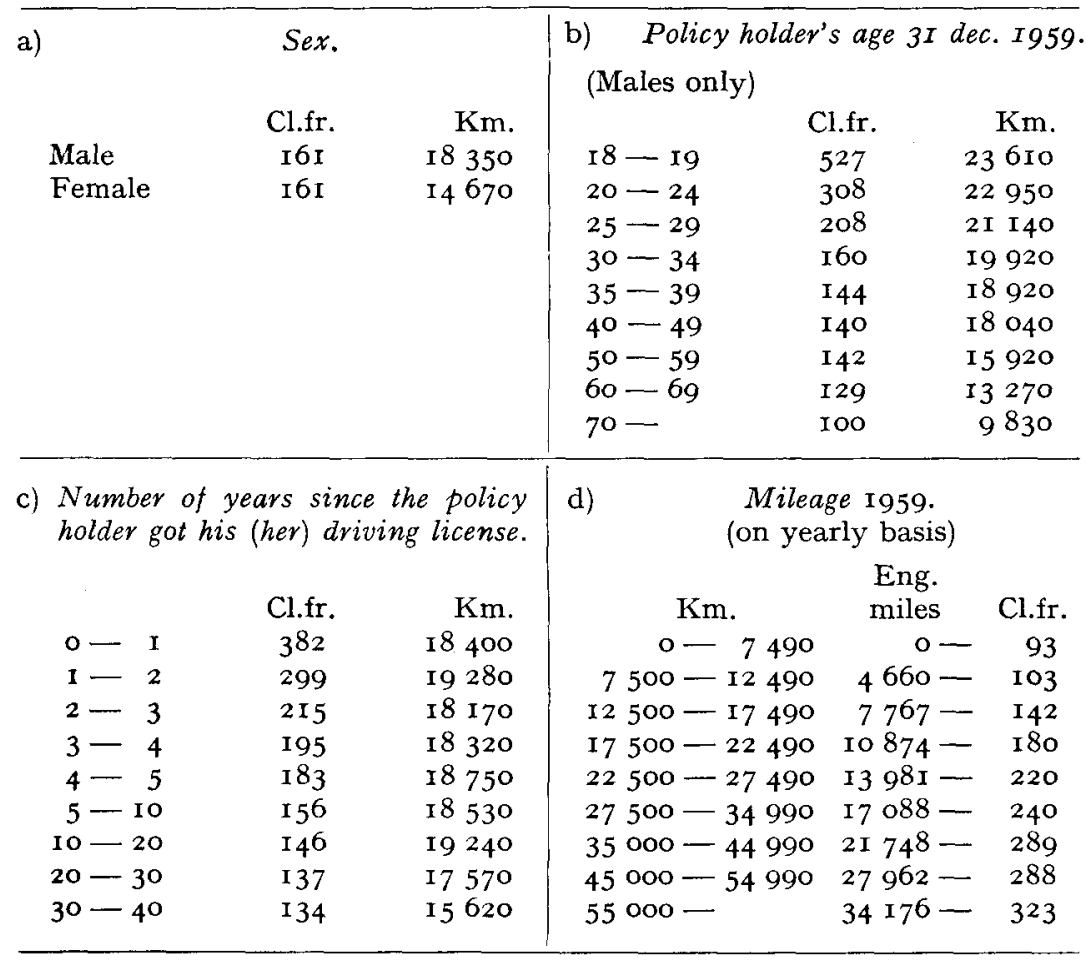

